Axel Schulz, Bernd Eisenstein, Marco A. Gardini, Torsten H. Kirstges, Waldemar Berg Grundlagen des Tourismus 

Axel Schulz, Bernd Eisenstein, Marco A. Gardini, Torsten H. Kirstges, Waldemar Berg

\section{Grundlagen \\ des Tourismus}

3., vollständig überarbeitete und ergänzte Auflage 
ISBN 978-3-11-064023-6

e-ISBN (PDF) 978-3-11-064121-9

e-ISBN (EPUB) 978-3-11-064131-8

Library of Congress Control Number: 2020946512

Bibliografische Information der Deutschen Nationalbibliothek

Die Deutsche Nationalbibliothek verzeichnet diese Publikation in der Deutschen Nationalbibliografie; detaillierte bibliografische Daten sind im Internet über http://dnb.dnb.de abrufbar.

(C) 2021 Walter de Gruyter GmbH, Berlin/Boston

Umschlaggestaltung: VLADGRIN / iStock / Getty Images Plus

Satz: le-tex publishing services $\mathrm{GmbH}$, Leipzig

Druck und Bindung: $\mathrm{CPI}$ books $\mathrm{GmbH}$, Leck

www.degruyter.com 